\title{
Comparative Research on Deep Learning Literatures of China Mainland with Other Regions
}

\author{
Hao Zhang* \\ Yangzhou University \\ Yangzhou Jiangsu, China \\ zhanghao@yzu.edu.cn
}

\author{
Xiujuan Wu \\ Zhejiang Yuexiu University of Foreign Languages \\ Shaoxing Zhejiang, China \\ yuzhu_2109@126.com
}

\begin{abstract}
The research on deep learning is long-standing and productive. This paper aimed at discovering the differences of the research between China mainland and other regions, and clarifying their developmental stages, status and trend. By means of content analysis, this paper comprehensively compared and analyzed the related literatures of deep learning in China mainland and other regions from the quantitative and qualitative perspective. The quantitative analysis show that research in other regions has already been at a mature stage of stable development, while research in China mainland is coming into an exploratory stage of rapid development; the results of qualitative analysis is that research in other regions mainly focus on the practical and empirical study, but research in China mainland is more concerned with the theoretical study; on the whole, both of them have systematically elaborated the connotation and process of deep learning, and is paying more attention to its promotion and evaluation, especially the use of technology.
\end{abstract}

Keywords-deep learning; content analysis; trend analysis; comparative analysis

\section{INTRODUCTION}

In the era of knowledge economy advocating quality education and comprehensive development, the research on deep learning has great practical significance. The ancients have already generated the idea of deep learning and realized its importance for a long time. Nowadays contemporary scholars have paid growing attention to deep learning and conducted in-depth study from different angles. In order to clarify the developmental venation, actuality and tendency of deep learning and know more about its development stages, key figures and major achievements, it is quite necessary to carry out a comprehensive and in-depth analysis of the status on the basis of the literature research. This paper will systemize the related literatures of deep learning in China mainland and other regions by means of content analysis, so that we can sum up the theoretical outcomes and practical experience, identify the problems and deficiencies that exist in the current study, and provide some advice for further study.

\section{ThE QUANTITATIVE ANALYSIS OF THE LiTERATURES}

The quantitative analysis of the literatures can help to discover its laws and stages of historical development and further predict its growth trends, so is to the research on deep learning. The distribution and growth of literatures about deep learning in China mainland and other regions is shown in figure 1.

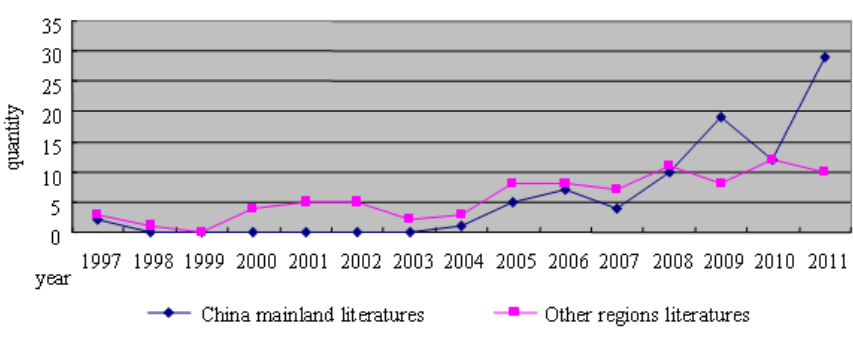

FIGURE 1. THE DISTRIBUTION AND GROWTH OF LITERATURES ABOUT DEEP LEARNING IN CHINA MAINLAND AND OTHER REGIONS

\section{A. Quantitative Analysis on Literatures of China mainland}

As shown in figure 1, the number of literatures about deep learning in China mainland is growing year by year. It indicates the study of deep learning in China mainland has developed greatly in the period and attracted more and more researchers' attention. However, its growth is unstable, for instance there is no related literature been retrieved for 6 years after the use of deep learning started in 1997, that is to say the research on deep leaning is basically at a standstill during this period; until 2004, deep learning comes into researchers' sight once again, and then its literatures increases gradually but not always steady, so research on deep learning in China mainland is not yet mature, and needs to be strengthened.

It seems that 2004 is an important turning point in the study of deep leaning in China mainland. The main reason is that the Association for Educational Communications and Technology or AECT for short revises the definition of educational technology in 2004, highlighting the ideas of deep learning, and putting its efforts into promoting students' deep learning and learning efficiency [1]. So as it is widely spreaded into the field of educational technology in China mainland, researchers begin to focus on deep learning again since 2004 especially after 2008.

\section{B. Quantitative Analysis on Literatures of Other Regions}

From figure 1, we can find that the number of literatures about deep learning in other regions is developing irregularly, and often increases or decreases by a small amount. From 2000 to 2004, the number of literatures per year is five or less, while between 2005 and 2011, its number maintains at 7 or more, and the largest number is only 12. It seems that the development of research on deep learning in other regions has entered into a 
stable but slower stage in recent years. The major reason may be that most of the results in other regions are drawn by the empirical research, while empirical research usually needs more time.

In fact, the research on deep learning has rapidly developed and gradually matured in the 1970s and 1980s, meanwhile has been conducted by four main groups of researchers: the Swedish group led by Marton, the Lancaster group led by Entwistle, the Australian group led by Biggs, and the Richmond group led by Pask[2]. Moreover during the 1970s, the research developed to a significant extent independently, and until the 1980s, each group has realized that the work is undertaken elsewhere, and began to affect each other for common development. Although there are great differences on their aims and results, all of them has found that whether for specific reading assignments or overall learning tasks, students often adopts two qualitatively different categories of learning approach - deep or surface learning[3].

\section{The Brief Summary}

The research on deep learning in other regions began in the mid-1950s, and formed a research summit in the 1970s and 1980s. In recent 12 years, the number of literatures in other regions develops irregularly and has entered into a stable, mature stage. In contrast, the research in China mainland started rather late than the other regions and still not mature, but in nearly 12 years as a whole, the number of literatures in China mainland is gradually increasing. It seems that the study of deep learning is emphasized by the researchers in China mainland, and has begun to come into the exploratory stage of rapid development.

\section{ThE QUALitATIVE ANALYSIS OF THE LITERATURES}

The content analysis of the literatures can help to establish theoretical system of the research and reveal its focus, maturity and developmental direction. Therefore, according to the content analysis and statistic analysis of the related literatures about deep learning in China mainland and other regions, we can know their focuses and differences. As shown in table 1, the total number of the achievements in China mainland is basically the same as other regions in recent 12 years, and the result of chi-square test also shows that the content of research in China mainland and other regions has no significant difference. It means that from a statistical point of view, researchers in China mainland and other regions pay the same attention to the three themes of deep learning, which is the research on theoretical cognition, practical application or technical support.

TABLE 1. THE CONTENT DIFFERENCES OF THE RESEARCH ON DEEP LEARNING IN CHINA MAINLAND AND OTHER REGIONS

\begin{tabular}{|c|c|c|c|c|c|c|}
\hline \multirow[b]{2}{*}{$\begin{array}{l}\text { Literature } \\
\text { Resourves. }\end{array}$} & \multicolumn{3}{|c|}{ Analyzing Items. } & \multirow[b]{2}{*}{$x^{2}$-value. } & \multirow[b]{2}{*}{ P-vahue. } & \multirow[b]{2}{*}{$\begin{array}{c}\text { Differeme. } \\
\text { Degree. }\end{array}$} \\
\hline & $\begin{array}{c}\text { Theoretical } \\
\text { Cognition. }\end{array}$ & $\begin{array}{c}\text { Fractical } \\
\text { Appricantion. }\end{array}$ & $\begin{array}{c}\text { Technical } \\
\text { Support. }\end{array}$ & & & \\
\hline China maimland. & 33. & 30. & 27. & \multirow{2}{*}{4.683.} & \multirow{2}{*}{$0.096=0.05$} & \multirow{2}{*}{ nom-significart } \\
\hline Other regions. & 20. & 40. & 29.1 & & & \\
\hline
\end{tabular}

A. Results of Qualitative Analysis on Literatures of China Mainland
Researchers in China mainland don't show particular concern on a certain topic of deep learning. By means of literature retrieval and analysis, we find that interiorly the mention of deep learning first appeared in the fields of practical application. That is, in 1997 there is a teacher, who proposed students to use the method of deep learning in intensive reading teaching, so that they can deep understand the content, thought and background of the reading materials [4]. Since then, on the basis of empirical research, researchers in China mainland have begun to analyze the application status and effect of deep learning, and combined with pedagogical practice to put forward some specific strategies which can promote deep learning, such as problem-based learning, task-driven learning, process evaluation, introspective reflection and so on.

In addition, descriptive research has comprehensively narrated the connotation, main characteristics and theoretical basis of deep learning. From the perspectives of the knowledge classification, information processing, experiential learning and reflective learning, the researchers have elaborated their understanding of deep learning. It agrees that deep learning can be explained and supported by the theories of constructivism, situated cognition, distributed cognition and meta-cognition, with the features that emphasize on the comprehensive learning, deep information processing, critical higher-order thinking, active knowledge building and transfer, and real problems solving[5]. And for the problems occurring in the process of education information, researchers also have begun exploring how to support deep learning by the means of information technologies, such as the blog, spreadsheet, concept map, Moodle learning platform and others.

\section{B. Results of Qualitative Analysis on Literatures of Other Regions}

The research on deep learning in other regions starts originally by Marton and Säljö who do experimental study on students' reading process, approach and outcome in the mid of 1950s [6], and always take the practical application as the research hotspot. Since then, the study of deep learning in other regions has been developing quickly and gradually maturing. However, there are very few purely theoretical studies among all the researches. Most researchers combine with the teaching of accounting, medicine, mathematics and other subjects, to explore the ways of promoting and evaluating deep learning by the empirical research such as survey, experiment and observation. For example, Tracy and Susan illustrate the practical significance when using the SOLO (the full name is Structure of the Observed Learning Outcome) taxonomy to promote and assess deep learning in the teaching of history, and thus improve the SOLO taxonomy proposed by the Biggs and Collins [7].

As we all know, technology has played an extremely important role in the development of our social and education, so is to the development of deep learning. Researchers in other regions have already conducted the practical and empirical research about how to support deep learning by technology, especially information technology for a long time. For instance, Singapore Institute for Learning Sciences carries out the researches in the middle and primary schools about how to 
create the technology-supported learning environment for the purpose of promoting deep learning, and develops five signature models about how to design the technology-supported learning environment [8]. The technology mainly refers to educational games, virtual worlds, intelligent agents, knowledge forum or handheld computers.

\section{The Brief Summary}

Above all, researchers in other regions pay more attention to the practical and empirical study. They usually design a specific experimental program based on their understanding of deep learning, to test the effect of deep learning strategies, extract practical experience in the experiment, and at last enrich the theories of deep learning. In contrast, research on deep learning in China mainland is more concerned with the theoretical study, that is to generate the basic theoretical system through experience, but most of the research results are lack of innovation. Meanwhile in pedagogical practice, strategies to promote deep learning have been put forward, but poor operational in actual condition and harder to test out their promoting effect to deep learning. Therefore, researchers in China mainland need to combine with specific pedagogical practices, and in-depth explore how to promote and evaluate deep learning, especially pay more attention to the use of technology.

\section{CONCLUSIONS}

Through the quantitative and content analysis of the deep learning literatures in China mainland and other regions, we find that after half a century the research on deep learning both in China mainland and other regions has got remarkable achievements and been maturing gradually, while there are some issues to be further studied. On the whole, researchers have formed a more perfect system of deep learning by the descriptive research on the status and outcomes of deep learning, but still lack of a systematic strategy to promote deep learning and the specific criteria to evaluate deep learning. In other words, researchers have systematically elaborated "what is deep learning" and "how to make deep learning happen", and now start to regard "how to promote and assess deep learning" as the core subject. Additionally, technology has always provided strong support for the education, and now so is for deep learning. Therefore when technology is becoming increasingly complex, researchers really need to study deep learning from the theoretical and practical point, explain how to support and promote deep learning by means of technology and verify their ideas through empirical studies.

\section{ACKNOWLEDGMENT}

This research is sponsored by New Century Human Resource Project of Yangzhou University.

\section{REFERENCES}

[1] Gang Lei, Research on the development trend of education technology from the evolution of AECT definition, China Educational Technology. 12,2008,pp.13-15.

[2] Beattie, B. Collins, B.Mcinnes, Deep and surface learning: a simple or simplistic dichotomy, Accounting Education. 6(1), 1997,pp.1-12.

[3] M. Prosser, K. Trigwell, Understanding learning and teaching: the experience in higher education, SRHE and Open University press, London,1999.
[4] Zhenru Ma, Research on how to use the reading theory to improve the effect of intensive reading teaching. Journal of Guangdong Education Institute, 3,1997,pp.89-91.

[5] Hao Zhang, Xiujuan $\mathrm{Wu}$, The study on the connotation and cognitive theory foundation of deep learning, China Educational Technology. 10,2012,pp.7-11.

[6] J.Biggs, C.Tang, Teaching for quality learning at university, The Society for Research into Higher Education\&Open University Press, Buckingham,2011,pp.21-22.

[7] T.W.Smith, S.A.Colby, Teaching for Deep Learning, the Clearing House, 80(5), 2007,pp.205.

[8] Cijie Lv, Wenli Chen, Study about how to put the research results of technology-intermediary learning into practice from the angle of learning science, China Educational Technology. 12,2007,pp.1-7. 